\title{
A LINGUAGEM POSTA À PROVA PELO TEMPO: CARLO GINZBURG E SUAS CONTRIBUIÇÕES PARA A HISTÓRIA DA EDUCAÇÃO
}

\author{
DOI: http://dx.doi.org/10.1590/2236-3459/71676
}

\author{
Rodrigo Ribeiro Paziani' \\ 'Universidade Estadual do Oeste do Paraná (Unioeste), Campus de Marechal Candido Rondon/PR, Brasil
}

\author{
Humberto Perinelli Neto" \\ "Universidade Estadual Paulista (Unesp), Campus de São José do Rio Preto/SP, Brasil
}

\section{$\cos 80$}

\begin{abstract}
Resumo
A produção historiográfica de Carlo Ginzburg parece estar cada vez mais consolidada no Brasil, a ponto de ser alvo de inúmeras análises, interpretações e críticas. Contudo, este historiador ainda é pouco conhecido pelo público acadêmico, com destaque para os intelectuais que se debruçam sobre história e história da educação. Partindo deste contexto, a proposta central deste artigo será a de promover reflexões sobre o "paradigma indiciário" proposto por Ginzburg. Para tanto, apresentamos o percurso formativo, as obras de cunho teórico-metodológico e as perspectivas analíticas deste historiador, bem como possíveis relações que se pode estabelecer com os domínios da Linguagem, especificamente a Análise do Discurso, caso da corrente representada por Michel Pêcheux.

Palavras-chave: Carlo Ginzburg, teoria da história, linguagem, análise de discurso, história da educação.
\end{abstract}

\section{LA LENGUAJE PUESTO A PRUEBA POR EL TIEMPO: CARLO GINZBURG Y SUS CONTRIBUCIONES A LA HISTORIA DE LA EDUCACIÓN}

\section{Resumen}

La producción histórica de Carlo Ginzburg parece estar cada vez más consolidada en Brasil, a punto de ser objeto de numerosos análisis, interpretaciones y críticas. Sin embargo, este historiador es aún poco conocida por la comunidad académica, especialmente los intelectuales que se centran en la historia y la historia de la educación. A partir de este contexto, el objetivo central de este artículo es promover la reflexión sobre el "paradigma probatorio" propuesto por Ginzburg. Por lo tanto, se presenta el curso de formación, las obras de la naturaleza teórica y metodológica y perspectivas de análisis de este historiador, así como las posibles relaciones que se pueden establecer en las áreas de lenguaje, específicamente el análisis del discurso, si la corriente representada por Pêcheux.

Palabras clave: Carlo Ginzburg, teoría de la historia, lenguaje, análisis del discurso, historia de la educación. 


\title{
LANGUAGE PUT TO THE TEST BY TIME: CARLO GINZBURG AND ITS CONTRIBUTIONS TO THE HISTORY OF EDUCATION
}

\begin{abstract}
The historiographical production of Carlo Ginzburg seems to be increasingly consolidated in Brazil, to the point of being the target of numerous analyzes, interpretations and criticisms. However, this historian is still little known by the academic public, with prominent intellectuals who focus on the history and history of education. Starting from this context, the central proposal of this article will be to promote reflections on the "indicial paradigm" proposed by Ginzburg. For that, we present the formative course, the theoretical-methodological works and the analytical perspectives of this historian, as well as possible relations that can be established with the Language domains, specifically Discourse Analysis, in the case of the current represented by Michel Pêcheux.

Keywords: Carlo Ginzburg, theory of history, language, discourse analysis, history of education.

\section{LE LANGAGE MIS À L'ÉPREUVE PAR LE TEMPS: CARLO GINZBURG ET SES CONTRIBUTIONS POUR L'HISTOIRE DE L'ÉDUCATION}

\section{Résumé}

La production historiographique de Carlo Ginzburg paraît être chaque fois plus consolidée au Brésil, au point d'être sujet d'innombrables analyses, interprétations et critiques. Cependant, cet historien est encore peu connu par la communauté académique, en particulier pour les intellectuels qui mettent l'accent sur l'histoire et I'histoire de l'éducation. À partir de ce contexte, la proposition centrale de cet article est promouvoir des réflexions sur le "paradigme indiciaire" de Ginzburg. Pour ce faire, nous présentons le cours de formation, les œuvres de la nature théorique et méthodologique et perspectives analytiques de cet historien, ainsi que les relations possibles qui peuvent être établies dans le domaine du Langage, spécifiquement l'Analyse du Discours dont le courant est représenté par Michel Pêcheux.

Mots-clés: Carlo Ginzburg, théorie de l'histoire, langage, analyse du discours, histoire de l'éducation. 


\section{Ginzburg, história e cultura: "pistas" deixadas por Saviani}

$\mathrm{H}$

á vinte anos, em Conferência proferida no IV Seminário Nacional de Estudos e Pesquisas "História, Sociedade e Educação no Brasil", Dermeval Saviani (1997) ${ }^{1}$ chamava atenção para o necessário exercício reflexivo envolvendo diálogos entre o debates historiográfico e a História da Educação. Para tanto, Saviani tomou "a própria História" como ponto de partida de suas discussões sobre a educação: em seu dizer tal escolha não parecia "coisa vã" (SAVIANI, 1997, p. 1), haja vista que "[...] o debate historiográfico tem profundas implicações para a pesquisa educacional, já que o significado da educação está intimamente entrelaçado ao significado da História". (SAVIANI, 1997, p. 14).

Tratava-se, em particular, de um diálogo travado com o livro "Domínios da História", publicado à época e organizado por Ciro Flamarion Cardoso e Ronaldo Vainfas (1997). A obra, considerada um importante referencial na área de História, compunha-se de uma coletânea de textos de vários intelectuais e dividida em três partes: uma primeira, constituída de "Territórios do Historiador" (História Econômica, História Social, História e Poder, História das Ideias e História das Mentalidades e História Cultural); uma segunda, intitulada "Campos de Investigação e Linhas de Pesquisa" (com vários caminhos, aqui não citados) e uma última, também contendo diferentes textos, nomeada de "Modelos Teóricos e Novos Instrumentos Metodológicos: alguns exemplos".

Num primeiro momento, Saviani centrou atenção para a "crise de paradigmas" vivenciada pelos historiadores ao final do século XX. Citando passagens do texto introdutório do mencionado "Domínios da História", o filósofo-educador reconhecia vivência daquilo que Cardoso chamava de paradigma "racionalista" versus paradigma "pósmoderno", muito embora discordasse do historiador, por colocar no primeiro bloco correntes teóricas distintas como marxismo, iluminismo e positivismo. Tomando por base as críticas de Cardoso aos estudiosos vinculados à voga "pós-moderna" (identificada como irracionalista, fragmentadora, relativista, subjetivista), Saviani sugeria aos historiadores da educação uma série de cuidados para não cair na principal armadilha dos "pós-modernos": a ausência de preocupação com questões teóricas e epistemológicas.

Num segundo, Saviani fez referência significativa ao desenvolvimento de estudos historiográficos, cada vez mais em voga no Brasil naquele momento, afirmando que estariam não apenas incorporando certos "modismos" intelectuais, como também influenciando os historiadores da educação. Menção especial é feita ao legado de Michel Foucault:

[...] em razão do mencionado empenho em se colocar em dia com os avanços no campo da historiografia, detecta-se uma tendência em aderir muito rapidamente às ondas supostamente inovadoras que aí se manifestam. Apenas à guisa de exemplo, lembro a influência de Foucault, transformado praticamente no guru da historiografia dita avançada. O problema é que a maioria dos historiadores, de um modo geral, e historiadores da educação, de modo especial, tem pouco domínio sobre o universo epistemológico em que se move Foucault e, menos ainda, sobre a matriz filosófica de que é tributário, o que obrigaria a remontar ao pensamento de Nietzsche. (SAVIANI, 1997, p. 15).

\footnotetext{
${ }^{1}$ Conferência de abertura intitulada "O debate teórico e metodológico no campo da história e sua importância para a pesquisa educacional".
} 
De um lado, certo abandono do referencial teórico e das questões epistemológicas fundamentais do "ofício do historiador"; de outro, a incorporação acrítica das "ondas supostamente inovadoras", exemplificadas na fácil recepção de Foucault no Brasil. Um perigo parecia (parece?) rondar o campo historiográfico: o avanço e a hegemonia do "pósmoderno" nos círculos acadêmicos.

A que (ou a quem) Saviani estaria se referindo? Em nosso entender, tendo em vista o diálogo com Ciro Flamarion, principalmente, aos historiadores ligados à chamada "História Cultural"2. Vinte anos após a conferência em questão, percebe-se que aquelas reflexões merecem ser revisitadas.

De lá pra cá, se tornou cada vez maior a influência de autores e obras vinculadas a História Cultural na produção acadêmica brasileira, a ponto de ganhar repercussão, nos anos 1990, o termo "Nova História Cultural"3 (alcunha em nada consensual). Prova disso é que vários estudos no próprio campo da educação têm sido elaborados a partir de intelectuais associados (às vezes, polemicamente) à História Cultural - casos de Edward Thompson, Roger Chartier, Jacques Le Goff, Michel Foucault e Hayden White. (SAVIANI, LOMBARDI, SANFELICE, 2005; CASTANHO, 2010; SANFELICE, 2010; VIEIRA, 2015).

Contudo, se de um lado essa vertente historiográfica possui um espectro amplo e diverso - o que provoca generalizações em sua abordagem - de outro, pode-se incorrer no erro (teórico!) de colocar indiscriminadamente no mesmo "balaio cultural" historiadores que estão longe de receberem o epíteto de "culturais".

Não será nosso interesse neste artigo deslindar os diversos "mundos" da (Nova?) História Cultural, mas discutir sobre esta historiografia a partir das "pistas" deixadas por Saviani, no que tange aos enfrentamentos teóricos e metodológicos que devem promover os historiadores da educação face à (suposta) crise de paradigmas. Para tanto, apresentaremos reflexões sobre o "paradigma indiciário" proposto por Carlo Ginzburg (1939-), tomando por eixos o percurso formativo, as obras de cunho teórico-metodológico e as perspectivas analíticas deste historiador italiano, bem como possíveis relações que se pode estabelecer entre suas obras e os domínios da Linguagem, mais especificamente a Análise do Discurso (AD), caso especial daquela representada por Michel Pêcheux.

\section{Proximidades afetivas e efetivas com a linguagem}

A princípio, compreender a relação que Carlo Ginzburg promoveu entre conhecimento histórico e os estudos da linguagem atentando a sua biografia implica em tomar cuidados indicados por ele próprio, quando numa de suas entrevistas destacou:

\footnotetext{
2 Por "História Cultural" (HC) entende-se, grosso modo, um movimento historiográfico de múltiplas origens (embora de visível hegemonia francesa/francófila) que se desenvolveu no interior dos Annales (BURKE, 1997; REIS, 2000), a partir da década de 1980, com a disseminação da "crise de paradigmas", que teria culminado com a "crise" das grandes narrativas e das teorias explicativas. Embora a HC dialogue criticamente com correntes teóricas do Estruturalismo (DOSSE, 2007a; 2007b) e possa até ser estendida não sem sérias discordâncias - a certos historiadores marxistas (HOBSBAWM, 1998; FONTANA, 2004), trata-se de uma historiografia urdida na esteira da "história em migalhas". (DOSSE, 1987).

${ }^{3}$ Não nos cabe aqui explanar longamente acerca da "Nova História Cultural". Basta dizer que é uma tendência historiográfica (de origem predominantemente norte-americana), surgida na década de 1990, que arrogouse a posição de produzir uma "nova" maneira de escrever história em perspectiva cultural (símbolos, representações, práticas, discursos). Seu representante mais conhecido talvez seja Lynn Hunt (1995) organizadora, inclusive, de livro que recebeu título homônimo a tal tendência.
} 
[...] devo dizer de antemão que, como historiador, sou um pouco cético sobre as explicações teleológicas que vêem os indivíduos como se fossem uma linha reta que vai, sem desvios, da infância a maturidade. É possível que haja elementos cruciais em minha história de vida, mas é bem provável que eu não possa vê-los. (BURKE, 2000, p. 272).

Contudo, mesmo atentos à sanha teleológica mencionada por Ginzburg, é impossível não traçar paralelos entre sua biografia e a maneira como promoverá o diálogo entre produção do conhecimento histórico e os estudos da linguagem.

Isto porque, desde pequeno, Carlo Ginzburg conviveu de modo ímpar com o universo das palavras e seus sentidos, seja por conta da relação dos pais com a escrita dados os estudos literários, as traduções e a composição de romances que promoveram seja em decorrência da própria trajetória acadêmica que este intelectual percorreu.

Em relação ao pai, Leone Ginzburg, cabe salientar que nasceu na cidade russa de Odessa, em 1909, viveu certo período da infância com a família entre Berlim e Turim, até migrar definitivamente para essa cidade italiana, onde completou sua formação escolar e graduou-se em Literatura Moderna pela Universidade de Turim, mesma instituição na qual passou a integrar o corpo docente (entre 1930 e 1934).

Um de seus colegas no Liceu de Turim foi Norberto Bobbio, que assim o descreveu:

La nostra classe, o per lo meno alcuni di noi, avevano acquistato una speciale sensibilità [...] per la presenza di un giovane precocissimo, che aveva, a quindici anni - quando entrò al d'Azeglio come studente di prima liceo - tal vastità di cultura, tal maturità di giudizio e tal altezza di coscienza morale da suscitar meraviglia nei professori - e uno di quei professori lo ha chiamato discepolo maestro - e schietta ammirazione, senza invidia, nei compagni: parlo di Leone Ginzburg. (BOBBIO, 2013, p. 124).

$\mathrm{Na}$ Universidade de Turim, Leone atuou como professor de literatura russa e línguas eslavas, além disso, foi um dos fundadores da Editora Einaudi (1933) e se tornou tradutor reconhecido, visto ser responsável por verter para o italiano obras russas como Ana Karenina, de Liev Tolstoi, e Taras Bulba, de Nikolai Gogol, entre outros.

Foi igualmente em Turim que Leone conheceu e se casou com Natalia Levi, assim como se dedicou a forte atuação política, com destaque para militância no "Partido da Justiça e Liberdade", para a fundação do clandestino "Partido de Ação", bem como para a edição do jornal "Itália Liberta".

O ativismo de Leone em pleno regime fascista gerou sua expulsão da Universidade de Turim (1934), sua prisão (1934 a 1936), a pena de exílio interno de sua família na vila de Pizzoli (entre 1940 e 1943) e, por fim, seu assassinato por tortura, praticado pelos nazistas numa prisão romana (em 1944).

A mãe de Carlo, Natalia Ginzburg, vivente entre 1916 e 1991, também possuía ascendência judaica (filha de Giuseppe Levi), foi tradutora de Marcel Proust e de Gustave Flaubert, entre outros, para o italiano e igualmente trabalhou na Editora Einaudi.

Tal como Leone, Natalia se dedicou ao ativismo político, como membro do Partido Comunista, sendo eleita, inclusive, deputada (1983 a 1991) e, como tal, se envolveu em temas como a redução do custo do pão, a assistência às crianças palestinas e a reforma das leis de adoção.

A contar de 1942, quando da publicação de La strada que vá in cittá, sob o 
pseudônimo de Alessandra Tornimparte, por conta do sobrenome judeu, Natalia se tornou reconhecida romancista/ensaista, traduzida em diversas línguas e responsável, posteriormente, pela escrita de obras aclamadas pelo público e pelos críticos, como La você dela sera, La famiglia Manzoni e Tutti nostri ieri.

Após a morte de Leone, Natalia se casou com o professor de inglês e crítico literário Gabriele Baldini (em 1950), mas prosseguiu com a carreira de romancista/ensaísta, fazendo parte de seleto grupo de intelectuais composto, entre outros, por Cesare Pavese, Italo Calvino, Giulio Einaudi, Elio Vittorini e Eugenio Montale.

Ao comentar sobre a tradução brasileira de seu romance "Caro Michelle", Patrícia Peterle assim resumiu a produção literária de Natalia Ginzburg:

\begin{abstract}
Seus primeiros livros são do final da década de 1940 e trazem sempre a memória como uma questão primária e necessária. Seu último livro, Serena Cruz o la vera giustizia (1990), é considerado pela crítica o mais engajado, um pamphelet sobre o problema da adoção [...].

Natalia Ginzburg marca profundamente com seu trabalho editorial a produção intelectual e literária da segunda metade do século XX. Os seus primeiros escritos saem, na década de 1930, na famosa revista Solaria, para a qual colaboraram tantos escritores. Um percurso de vida marcado pelo antifascismo, posicionamento político que já via no pai, Giuseppe Levi, e que depois irá compartilhar com o primeiro marido, Leone Ginzburg, que, preso pelo regime fascista, morre, como tantos outros, no cárcere de Regina Coeli, em 1944. Uma geração marcada, como tantas outras na Europa e na América Latina, pelo signo da censura e de um estado de exceção, mas que na verdade era a regra geral, para lembrar as palavras de Walter Benjamin. (PETERLE, 2012, p. 332).
\end{abstract}

Levando-se em conta a trajetória de seus pais, não representaria coincidência o fato de Carlo Ginzburg envolver-se com reflexões associadas ao campo da linguagem.

Numa entrevista concedida em 1998 (PALLARES-BURKE, 2000, p. 269-306), Ginzburg afirma que pretendeu se tornar um escritor, como sua mãe, e que, após desistir desta carreira e se dedicar a história, se valeu da experiência dela para pensar num outro tipo de público leitor de seus textos (para além do acadêmico).

Não obstante, deve-se reconhecer também que a atenção para com os estudos da linguagem não se fizeram presentes nos textos de Carlo Ginzburg apenas por conta do peso de suas relações familiares, mas também - de maneira especial - pelo pertencimento a uma geração de estudiosos profundamente marcada pela relação existente entre discurso, poder e sociedade.

\title{
No olho do furacão, mas ao seu modo
}

Jovem intelectual formado ao longo das décadas de 1950 e 1960, Ginzburg construiu seu ethos acadêmico na Universidade de Pisa, onde vivenciou uma formação inicial fortemente calcada nas humanidades (literatura, filosofia e história), aprofundada, posteriormente, pelas experiências de pesquisa e de docência travadas no Instituto Aby Warburg, em Londres, e na Universidade de Bolonha.

$\mathrm{Na}$ condição de acadêmico italiano, Ginzburg vivenciou debates marcados pela presença das ideias de dois estudiosos, de modo especial: Benedetto Croce (com quem não se identificou) e Antonio Gramsci.

Aqui cabe um parêntesis: leitor de Marx na juventude, embora não seja um marxista 
e reconheça, com honestidade intelectual, ser "muito ignorante" (palavras suas) a respeito das obras marxianas (PALLARES-BURKE, 2000, p. 301), Ginzburg sofreu influências deste pensador - casos das relações entre "ser social" e "consciência social", do protagonismo dos sujeitos históricos e da história feita de tensões e conflitos (HOBSBAWM, 1998, p. 171176) - e do marxismo gramsciano, a quem deve a opção de analisar os sujeitos marginalizados e as produções culturais, que, reunidos, agregam os estudos deste filósofo a chamada "cultura popular". (GRAMSCI, 2001).

Além disso, durante sua formação acadêmica, vale sublinhar que Ginzburg foi influenciado, de um modo geral, por autores e reflexões associadas ao domínio epistemológico, haja vista a significância dos debates promovidos naquelas décadas sobre temas como história, verdade, ciência e método, com destaque para as obras de Paul Ricoeur (1968) e Hans-Georg Gadamer (1997).

Por conta disso, sem mais delongas, passamos a indicar de modo focalizado os estudos e estudiosos que teriam exercido influência sobre o jovem Carlo Ginzburg, especificamente os que Ihe despertaram atenção para a importância da compreensão da linguagem no desenvolvimento das pesquisas históricas.

A primeira influência envolve certa tradição presente em Delio Cantimori:

Ao iniciar meus estudos na Scuola Normale, em Pisa, pensava em trabalhar com história da literatura, tornar-me um literato. E havia um seminário de um professor que ensinava em Florença chamado Delio Cantimori, um dos historiadores mais importantes da Itália. Ele ia passar uma semana em Pisa, e disse que iria ler e comentar a obra de Burckhardt, Considerações sobre a história do mundo. Lembro-me muito bem do momento em que o vi pela primeira vez: era um homem gordo, não muito alto, de barba branca, com uma cara de cardeal, como nos retratos de cardeais de El Greco. Falava com uma voz pastosa, e perguntou: "Algum de vocês lê alemão?" Muito poucos liam. Ele continuou: "Bom, vamos ler o livro de Burckhardt, mas vamos comparar as traduções italiana, francesa, inglesa etc." Começamos, e depois de uma semana tínhamos lido cerca de dez linhas. Aquilo me marcou profundamente. Aquela maneira de ler o texto levantando uma multiplicidade de problemas foi algo que me pareceu realmente magnífico. (GINZBURG, 1990, p. 255, grifos nossos).

Ginzburg apreendia com intelectuais como Cantimori - além de Erich Auerbach, Leo Spitzer e Gianfranco Contini, entre outros - a importância da filologia, isto é, do entendimento de textos a partir da associação entre erudição e leitura lenta e detalhada, já que esse expediente é capaz de oportunizar a captura profunda dos sentidos presentes nos textos, sem abrir mão, para isso, de posicioná-los contextualmente.

A segunda diz respeito a Marc Bloch, que he instigaria a enfrentar temas marginais, na busca de reflexões sobre problemas mais amplos, bem como Ihe inspiraria a prática da alteridade no enfrentamento dos discursos constituintes das fontes de pesquisa. Além disso, destaca-se o fato de Marc Bloch postular a construção do conhecimento histórico pelo reconhecimento de sua incompletude, por extensão, da presença da dúvida e da busca incessante pela verdade, o que significa refinar os instrumentos teóricos e metodológicos empregados na leitura das fontes, como sugere o próprio Bloch na seguinte passagem:

Em que medida, contudo, nos é permitido pronunciar esta palavra solene: certeza'? A crítica dos documentos não conseguira alcançar a certeza 'metafísica', conversa já Mabillon. Não deixava de ter razão. É só por simplificação que substituímos algumas vezes uma linguagem de probabilidade por uma linguagem de 
evidência. [...]. 'O acontecimento fisicamente impossível', disse Cournot, 'não é mais do que o acontecimento cuja probabilidade é insuficientemente pequena'. Limitando a sua parte de segurança a dosar o provável e o improvável, a crítica histórica não se distingue da maior parte das outras ciências senão por um escalonamento dos graus indubitavelmente mais matizado. (BLOCH, s/d, p. 117, grifos nossos).

A terceira influência é expressa por Ginzburg quando menciona o impacto sofrido por conta da leitura de obra de Federico Chabod:

Li o livro de um historiador italiano muito importante, Federico Chabod, sobre a
história religiosa do Estado de Mião no século XVI e as primeiras reações à
Reforma Protestante. Havia ali páginas admiráveis, e sobretudo uma, que me
impressionou muito da primeira vez que a li. Chabod havia trabalhado
intensamente com os arquivos milaneses, e tinha encontrado uma minuta de
documento oficial em cujo verso havia algumas frases sobre a predestinação
que haviam sido riscadas. E Chabod fazia uma análise maravilhosa desse
documento esquecido, riscado, quase destruído, em cujo verso alguém, talvez
um pequeno funcionário anônimo, havia escrito aquelas palavras. Chabod
dizia que esse funcionário poderia, como encontramos muitas vezes nos arquivos,
ter feito desenhos obscenos ou ter escrito palavras soltas, mas suas preocupações
religiosas estavam tão presentes que o levaram, num momento de tédio, a escrever
aquelas palavras que lá estavam. A análise de Chabod era realmente
extraordinária, sobretudo sua idéia de recuperar um documento como aquele
para a história. Hoje, pensando retrospectivamente, acho que naquele momento,
mesmo de uma forma obscura, compreendi o que se podia fazer com a história.
(GINZBURG, 1990, p. 256, grifos nossos).

Distanciando-se da tendência de se promover nas Ciências Humanas estudos preocupados com o entendimento de comportamentos padrões, de gestos coletivos e apreensões sociais generalizantes, tão em voga no período compreendendo as décadas de 1950 a 1970, Ginzburg passava a se dedicar ao estudo do particular, considerando a possibilidade de nele traçar, ao mesmo tempo, o entendimento do individual e do coletivo, servindo-se, para isso, de atenção para com os detalhes presentes na linguagem.

O estágio vivenciado por Ginzburg no Instituto Warburg, em Londres, durante a década de 1960, permitiu desenvolver ainda mais a preocupação com essa abordagem do particular, à medida que lhe proporcionou estendê-la para a leitura de fontes iconográficas e visuais.

A quarta influência direta sobre os trabalhos de Ginzburg remete a linguistas como Fernand Saussure, Roman Jakobson e Mikhail Bakhtin: os dois primeiros por Ihes ter permitido visualizar as permanências, enquanto o terceiro por colaborar para que entendesse as lutas simbólicas entre grupos sociais distintos, bem como as apropriações construídas pelo individuo, quando promove a leitura cruzada da cultura baixa e da cultura alta, incorrendo na produção intertextual, por meio da circularidade cultural.

A respeito de Saussure e Jakobson, nota Henrique Lima que:

Ginzburg assumia a analogia entre a "cultura" e a "língua" em modos semelhantes aos da antropologia estrutural (que a havia colhido, por sua vez, na lingüística estrutural de Roman Jakobson e Ferdinand Saussure). A célebre distinção elaborada por Saussure entre langue (a estrutura formal e inconsciente da língua) e a parole (a palavra, o uso singular da língua pelos indivíduos), assumida pela antropologia estrutural, era também encampada por Ginzburg. Contudo, à diferença da antropologia estrutural - que havia se voltado apenas para a langue, isto é, as "estruturas elementares", ignorando as variações 
como irrelevantes -, Ginzburg interrogava simultaneamente as "possibilidades latentes" da cultura e os modos pelos quais eram efetivamente vividas por Menocchio, colocando no centro da sua atenção precisamente o "singular" ignorado pela análise estrutural. Assim, o que estava em jogo não era apenas estabelecer as relações entre cultura camponesa e a cosmogonia de Menocchio dissolvendo a segunda na primeira, mas, ao contrário, investigar exatamente a complexidade das relações que se estabeleciam entre ambas. (LIMA, 2006, p. 327, grifos nossos).

Já sobre Bakhtin, Ronaldo Vainfas ressalta que:

Bakhtin percebeu com brilho a possibilidade de se resgatar a cultura das classes populares na França daquele período através da obra de um letrado, percebendo nisso um conflito de classes no plano cultural - e. mais precisamente, a carnavalização da cultura austera das elites no vocabulário da praça pública e no escárnio popular. Ginzburg procedeu do mesmo modo, embora tenha estudado não um intelectual das elites, mas um simples moleiro que sabia ler. E o historiador foi além, ao propor abertamente o conceito de circularidade, noção somente implícita em Bakhtin, que se preocupava mais com as oposições do que com as interpenetrações culturais entre as classes. (VAINFAS, 1997, p. 152, grifos nossos).

Finalmente, cabe registrar o diálogo que travou com Sigmund Freud, assim apresentado pelo próprio Carlo Ginzburg:

Sim, ele foi muito influente em minha obra, não tanto por suas reflexões teóricas,
mas por seus estudos de caso - relatados em seus Psicopatologia da vida
cotidiana -, que me fascinam enormemente. Devo a Freud algumas idéias que foram
particularmente valiosas para minha postura pessoal: primeiro, a de que a verdade
é dolorosa mas precisa, mesmo assim, ser enfrentada; segundo, a idéia de que é
possível combinar o positivismo com a abertura ao irracional. Desde muito cedo em
meus trabalhos me empenhei em enfrentar a tensão entre o racional e o irracional,
analisando os comportamentos e as crenças irracionais a partir de uma perspectiva
racional. Contra a tendência de se achar que a abordagem adequada é aquela que
imita o conteúdo, ou seja, que o irracional não pode ser abordado por uma
perspectiva racional, sempre defendi a importância de se desvendar a racionalidade
do irracional. E isso implica tanto envolvimento emocional quanto distanciamento.
(PALLARES-BURKE, 2001, p. 301, grifos nossos).

Refutando conceitos e conclusões traçadas por Freud - dado que baseadas numa compreensão despreocupada com a história -, dedicou-se Ginzburg a extrair das obras escritas por ele lições a respeito de como providenciar a leitura dos discursos enunciados e constituintes do Outro, mesmo quando considerados irracionais. Mais: Lendo Freud é que Ginzburg se convenceu da importância contida no estudo de casos, por meio da atenção aos detalhes, ao periférico e ao aparentemente insignificante, haja vista que, insistia o próprio Freud: "esforço-me no estudo do particular e espero que o geral se desprenda dele por si mesmo", visto que "o progresso do conhecimento não tolera tampouco definições rígidas". (LIMA, 2007, p. 01-02).

Todas estas colaborações seriam somadas por Carlo Ginzburg para elaboração de método por ele definido, originalmente, como "paradigma semiótico", mais que foi consagrado, na verdade, como "paradigma indiciário".

Curiosamente, Ginzburg se tornou um intelectual fortemente marcado pelos grandes debates epistemológicos ocorridos no século XX, sem se filiar a nenhuma corrente especifica, o que lhe permitiu extrair várias contribuições para seu oficio de historiador, ao conceder incessantes e generosos espaços às demais Ciências Humanas, especialmente 
no que tange a problematização da linguagem.

A recusa sempre expressa por Ginzburg aos rótulos (o de micro-historiador, por exemplo), sua luta contra a especialização (revelada em frases como "euforia da ignorância" e "Gosto de dizer que sou um especialista em qualquer coisa"), bem como a defesa que promove das vantagens da posição periférica ("percebo as virtudes e as potencialidades intelectuais de olhar as coisas a distância, como um estranho") explicam o que lhe permitiu se tornar quem é e o quanto isto ainda lhe é caro.

Desta revisitada erudição, é possível dizer que algumas das preocupações teóricas e procedimentos metodológicos adotados por Ginzburg guardam certa proximidade com os estudiosos da $A D$, campo de estudos sempre em constante modificação e amparado em diferentes contribuições e interesses. Para ampliar as reflexões sobre o denominado "método indiciário", passaremos a entende-lo num comparativo com escritos da AD.

\section{O indiciarismo como lócus da interlocução}

Em "Sinais: raízes de um paradigma indiciário" - texto publicado no livro "Mitos, emblemas, sinais" (2007a) - Carlo Ginzburg propôs o desafio de reconstruir histórica e epistemologicamente um modelo interpretativo que emergia "silenciosamente" no interior das Ciências Humanas a partir do final do século XIX. (COELHO, 2006).

Tomando como referenciais de análise os domínios das artes figurativas (o médico e especialista em arte, Giovanni Morelli), da psicanálise (o médico e psicanalista Sigmund Freud) e da literatura (o médico e literato Arthur Conan Doyle) - Ginzburg tratou de problematizar tal modelo interpretativo, denominando-o de "paradigma semiótico", ou, mais especificamente, de "paradigma indiciário" - que "até agora (1986) não se prestou suficiente atenção”. (GINZBURG, 2007a, p. 143).

Contrapondo-se ao chamado "paradigma galileano" - método racionalista e quantificador com origens na Europa do século XVII, que excluía do pensamento e da prática científicas o lugar heurístico dos sujeitos e de suas significações de mundo, bem como substituía a indução e as conjecturas pelas hipóteses dedutivas e explicações causais (GINZBURG, 1989) - o paradigma indiciário teria como foco principal "examinar os pormenores mais negligenciáveis", de modo a encontrar nos elementos mais imperceptíveis e triviais, indícios de problemas - ou sintomas, na metáfora médica - amplos e profundos. (GINZBURG, 2007a, p. 144).

Daí suas comparações entre o conhecimento médico e o histórico, deste com o do detetive (os sinais, as minúcias) e do psicanalista (os resíduos do inconsciente), ou ainda os diálogos junto a semiologia, a filologia e a história da arte - campos do conhecimento que flertam constantemente com o gosto pelos detalhes (semânticos, léxicos, sígnicos, estéticos) aparentemente banais, porém reveladores de subjetividades, intenções, valores, sentidos e sintomas pouco ou não observados. (GINZBURG, 2007a, p. 08).

Conforme já explicitado nestas páginas, sua formação literária "de berço", somadas às influências acadêmicas nos domínios da linguagem, podem ser consideradas os mananciais epistemológicos por onde desaguaram muitos de seus escritos sobre 0 indiciarismo e o método (micro)analítico que o sustenta.

Mas é a partir da abordagem indiciária de Ginzburg - que dialoga não apenas com os campos da linguagem, mas também com a antropologia e a filosofia - que problemas 
inerentes ao campo científico (e mesmo extra-científico) passaram a ser levantados com maior rigor e erudição, sem, contudo, descartar os traços de sensibilidade e criação, indissociáveis da "arte" de narrar da (a) História.

Desta abordagem é que surgiu a preocupação em aprofundar não somente a análise minuciosa e lenta dos textos, mas, principalmente, os nexos entre os textos e seus diferentes contextos, o que permite captar os sentidos profundos no interior dos textos, uma vez que são mapeados o lugar social de produção, os sujeitos produtores de sentidos e a temporalidade histórica que os envolvem.

Neste âmbito, os nexos entre texto-contexto referem-se a um olhar aberto ao múltiplo, ao plural, ao complexo - fruto de seus diálogos críticos entre história e literatura ao mesmo tempo em que conduzem Ginzburg a deter-se, qual um lince, nas possibilidades retóricas (e poéticas) e nos procedimentos narrativos existentes em cada texto (ou conjunto de textos). Isto o aproxima de certos estudos de Análise do Discurso, bem como (e notadamente) das correntes hermenêuticas dos séculos XIX e XX.

É sabido que na trajetória de Ginzburg são marcantes as contribuições epistemológicas de correntes hermenêuticas tributárias de Gadamer (no campo cientifico), de Auerbach (campo literário) e de Ricoeur (num campo intermediário) - defensora, portanto, de uma "hermenêutica de textos" não mais reduzida à mera arte da interpretação (em sentido clássico), nem a um método específico aplicável às Ciências Humanas (como queria Dilthey), mas aquela que procura ressignificar o estatuto da verdade, levando em consideração as dimensões históricas e lingüísticas da experiência humana. (GRONDIN, 2012).

Assim, o método indiciário proposto por Ginzburg para analisar detidamente os sentidos menos visíveis presentes nos textos - e, portanto, capazes de revelar outros espaços de experiência e horizontes de expectativa em um determinado contexto histórico - não abdica da tarefa de revalidar o estatuto de verdade no campo historiográfico, porém, submetendo-o criticamente aos procedimentos teóricos e metodológicos da narrativa, presentes, por exemplo, nos escritos de Paul Ricoeur. (RICOEUR, 1997; BARROS, 2012).

Mas, ao atribuir valor heurístico ao tempo vivido, experenciado, e re-introduzir a sensibilidade e ação humanas no interior da narrativa histórica, Ginzburg, diferentemente de Ricoeur, não deseja criar (ou recriar) uma hermenêutica de pretensão universal, e sim partir de condições específicas de produção de textos em contextos históricos também específicos por sujeitos (indivíduos e/ou grupos sociais) marcados por peculiaridades histórico-culturais para, através desta trama, desvendar sentidos ocultos e reveladores e problematizar temas e questões amplas e profundas de uma época. É através deste procedimento, por exemplo, que ele situa a questão da linguagem e do discurso.

Tal procedimento parece combinar com a Análise de Discurso, especialmente a linha norteadora de Michel Pêcheux (GADET; HAK, 1997; MARTINS, 2004; ORLANDI, 2012) - que se preocupa tanto com o que está "por trás" (o problema ideológico) de um discurso, materializado em um texto, qualquer que seja a sua natureza, quanto sobre "como" e "em quê" condições (inclusive sócio-históricas) esse discurso é (ou foi) produzido pelos sujeitos. Como afirma Eni Orlandi (2013, p. 30):

Os dizeres não são... apenas mensagens a serem decodificadas. São efeitos de sentidos que são produzidos em condições determinadas e que estão de alguma forma presentes no modo como se diz, deixando vestígios que o analista do 
discurso tem de apreender. São pistas que ele aprende a seguir para compreender os sentidos aí produzidos, pondo em relação o dizer com sua exterioridade, suas condições de produção [...]. (grifos nossos).

Domitrovic reforça esse diálogo (2011), ao dizer que a compreensão das marcas discursivas enquanto pistas requerem dos analistas de discurso uma não-aplicação de regras pré-existentes. Os estudos de $A D$ devem levar em consideração o fato de que as pistas possuem um caráter conjectural, e, portanto, sujeitas a re-elaborações. Ou ainda, Maria Gregolin, quando afirma ser a AD um campo de estudo teórico-metodológico fundamental para deslindar os "acontecimentos discursivos", na medida em que toma como objeto "a produção de efeitos de sentido, realizada por sujeitos sociais, que usam a materialidade da linguagem e estão inseridos na história". (GREGOLIN, 1997, p. 13).

Como podemos perceber, as aparências enganam...

O indiciarismo de Ginzburg pode ser visto como um método de análise discursiva na qual o historiador, por exemplo, deve dedicar-se a tarefa de ler e interpretar intensivamente as fontes coletadas, vendo estas enquanto "discursos" que o auxiliem na compreensão das intenções subjetivas e dos expedientes narrativos presentes em um determinado "texto" (ou conjunto de "textos"), tanto em sua dimensão discursiva propriamente dita, quanto na dimensão extradiscursiva (a não-transparência da linguagem).

É o que podemos inferir da proposta metodológica de "O queijo e os vermes". Nele, Ginzburg, numa atividade meticulosa de pesquisa documental, encontrou em meio a uma massa de registros inquisitoriais um moleiro de nome Domenico Scandella - conhecido pela alcunha de 'Menocchio'. Partindo deste protagonista (então) anônimo da História, debruçou-se sobre a "cosmovisão" de Menocchio sobre a origem do mundo e das coisas construída em meio às mudanças e crises históricas do século XVI, ao abordar problemas de ordem geral, como a Reforma e a Contra-Reforma, o surgimento da imprensa num contexto de predomínio da oralidade e a influência recíproca entre a cultura das "classes subalternas" e da "cultura dominante". (GINZBURG, 2006, p. 18).

Entretanto, o que mais nos interessa é a entronização do método indiciário na operacionalização de um "enredo microscópico" (VAINFAS, 2002, p. 77) - narrativa densa que mescla criticamente o histórico e o ficcional (caso de "O queijo e os vermes") - no intuito de fazer emergir sinais ou pistas que revelem discursos e contra-discursos materializados na tessitura da escrita e que são, de algum modo, negligenciáveis aos olhos de um leitor pouco atento.

Por meio deste expediente metodológico, Ginzburg tem procurado investir em pesquisas qualitativas de fontes documentais controversas - no caso de Menocchio, os registros inquisitoriais - de modo a: 1. polemizar com os positivistas quanto as intencionalidades subjetivas inerentes ao processo de "fabricação" dos textos e 2. discordar dos céticos (os "pós-modernos") quanto a impossibilidade de aproximar-se do "real", mesmo que ele se apresente de maneira contraditória e/ou ambígua nos discursos daqueles que o enunciam. (GINZBURG, 1989, p. 209-210).

Há ainda um terceiro ponto na argumentação de Ginzburg: a necessidade imperiosa de percebermos, através de estudos intensivos das fontes, uma multiplicidade de indícios promotores de "defasagens", "desvios" e "apropriações" nos procedimentos de leitura de mundo por indivíduos e/ou grupos sociais anônimos em meio às "normas" e "regras" textuais subjacentes aos agentes e instituições "oficiais" de poder: 
A defasagem entre os textos lidos por Menocchio e o modo como ele os assimilou e os referiu aos inquisidores indica que suas posições não são redutíveis ou remissíveis a um ou outro livro [...] Mesmo que Menocchio tenha entrado em contato, de maneira mais ou menos mediada, com ambientes cultos, suas afirmações em defesa da tolerância religiosa, seu desejo de renovação radical da sociedade apresentam um tom original e não parecem resultado de influencias externas passivamente recebidas [...]. (GINZBURG, 2006, p. 23, grifos nossos).

No trecho destacado acima, sublinhamos a palavra "passivamente". Os procedimentos de leitura de Menocchio eram frutos de inúmeras operações de "recepção" de uma diversidade de "textos" (discursos) - almanaques, livretos, contos, canções, vidas de santos, passagens da Bíblia, fragmentos de obras reformistas - que chegaram até ele por meio da influência da cultura oral em suas interpretações, transformando-as em "filtros de memória" que fundiam, modelavam e deformavam os sentidos dos textos lidos. (DUARTE, 1998, p. 67-68; GINZBURG, 2006, p. 89).

Contudo, o moleiro não sofrera simplesmente "influências externas". Pelo contrário: em meio aos discursos (e às 'ideologias') disponíveis no "circuito cultural" da época, ele parecia (re)elaborar, mesmo que contraditoriamente, uma concepção peculiar - porém não exclusiva - do mundo ao qual vivia (o universo da cultura camponesa).

Esta análise deixa evidente o quanto a hermenêutica oriunda da filosofia da linguagem transformou-se num procedimento teórico e metodológico fundamental para Ginzburg não cair nas armadilhas do estruturalismo e do individualismo. Uma das fontes mais significativas na formação intelectual do italiano adveio das contribuições de Bakhtin, através de conceitos como os de "heteroglossia", "circularidade" e "polifônia", utilizados pelo russo em várias de suas obras, com destaque para "A Cultura Popular na Idade Média e no Renascimento: o contexto de François Rabelais" (1965; 1987). Apesar das influências formalistas e até estruturalistas, Bakhtin soube explorar a multiplicidade de vozes, saberes, valores e práticas inerentes ao contexto histórico de emergência do mundo moderno, ao tomar como referencial de análise os textos cômicos produzidos por Rabelais. (BURKE, 2005).

A partir das lições de Bakhtin, Ginzburg explorou com profundidade as questões da circularidade e da heteroglossia e suas interfaces com a história da cultura. É possível perceber essas questões quando analisamos os diálogos travados entre os juízes da Inquisição e os discursos enunciados por Menocchio, especialmente a partir de 1583, quando foi denunciado ao Santo Ofício, sob a acusação de proferir, segundo os textos dos juízes, palavras heréticas e impudicas sobre Cristo e a Igreja Católica.

Ginzburg chama atenção para um "saber religioso" do moleiro que era, no mínimo, estranho (e por vezes, ininteligível) à linguagem doutrinária do catolicismo, mas que, simultaneamente, acabava por gerar "efeitos de sentido" aos juízes, às testemunhas e ao próprio Menocchio. Vejamos essa passagem:

[...] Durante quatro longos interrogatórios $(7,16,22$ de fevereiro e 8 de março) ele se manteve firme diante das objeções do vigário, negou, fez comentários, rebateu. 'Consta no processo', disse-lhe o vigário Maro, 'que teria dito não acreditar no papa, nem as regras da Igreja, e que não sabia de onde saia tamanha autoridade de alguém como o papa'. Menocchio retrucou: 'Eu peço a Deus onipotente que me faça morrer agora se eu disse isso que Vossa Senhoria afirmou'... 'Eu disse', explicou Menocchio, 'que é preciso tentar fazer todo o bem até quanto se está neste mundo, porque depois é o Senhor quem governa as almas [...] As almas não vêm pegar as 
orações e as esmolas. Fica à majestade de Deus receber essas boas obras em benefício dos vivos ou dos mortos'. Ele imaginava que essa fosse uma hábil explanação, mas de fato contradizia a doutrina da Igreja em relação ao purgatório. (GINZBURG, 2006, p. 39).

A circularidade cultural de ideias (e ideologias) presente no discurso de Menocchio - a apropriação e releitura de textos doutrinários, versões popularizadas da Bíblia e folhetins de cunho protestante misturada a sua experiência de moleiro vivente no interior de uma cultura camponesa - não geravam apenas uma visão peculiar de mundo, como também contradições inerentes a essa mesma visão e que extrapolavam o campo discursivo. Ao mesmo tempo, a polifonia de vozes (discursos) incorporadas pelo moleiro - geradora de questionamentos por parte dos juízes - formava o "cosmos" por onde ele tentava justificar seus pensamentos e práticas. Podemos vislumbrar essa perspectiva quando as testemunhas disseram perante os juízes acerca do desejo de Menocchio de "falar contra os superiores" sobre suas "más obras". O moleiro, aliás, confirmava a suspeita das testemunhas:

[...] 'É verdade, eu disse que, se não tivesse medo da justiça, falaria tanto que iria surpreender; e disse que, se me fosse permitida a graça de falar diante do papa, de um rei ou príncipe que me ouvisse, diria muitas coisas e, se depois me matassem, não me incomodaria' [...]. (GINZBURG, 2006, p. 40).

Ao lado das ideologias inerentes aos discursos produzidos pelos juízes - e reforçadas pelo contexto histórico de perseguição aos heréticos - a "cosmovisão" do moleiro (eivada de apropriações de múltiplas ideologias) funcionava como uma espécie de "pêndulo discursivo", que ora se movimentava no sentido de tentar "enquadrar-se" ao que os juízes desejariam ouvir, ora destoava completamente do campo discursivo dos inquisidores, ao gerar "rupturas" ou "ruídos" como o atestado acima - momento contraditório, pois propicio a novos interrogatórios.

\section{0 indiciarismo enquanto distanciamento}

Atentar para as "rupturas" e os "ruídos" nos leva a segunda questão envolvendo Carlo Ginzburg e a AD: por que este estudioso tem defendido, de forma bastante insistente, as relações intrínsecas entre retórica e prova?

Em "Relações de força" (2002), o historiador italiano rediscute o problema da "verdade" (sua busca e sentidos), através das relações entre retórica e prova no campo da História. Neste terreno, o debate é inevitável. Segundo o italiano, a perspectiva de que os historiadores - e os intelectuais das Ciências Humanas - "possam provar algo parece a muitos antiquada e até ridícula”. (GINZBURG, 2002, p. 13).

Embora seja um problema de raízes antigas, a retórica ou a dimensão narrativa no mundo (pós?) moderno teria se autonomizado face a questão da prova. Falar em "prova" nos conduz ao terreno das evidências, ou seja, dos indícios (e as análises destes) que nos possibilitam a construção de um conhecimento "verdadeiro". O que isto implica?

Em primeiro lugar, que a evidência histórica não pode ser uma parede cega que nos impede de olhar para fora, para além da própria evidência e do discurso que a enuncia. Ela se assemelharia mais a um "espelho distorcido", no qual ao historiador caberia a tarefa de "descobrir para que lado ele está distorcendo", já que "esse é o único meio de ter acesso 
à realidade". (PALLARES-BURKE, 2000, p. 298).

Segundo lugar:

Outro problema... é o que se relaciona ao "conhecimento localizado" [...] já que este envolve um sério perigo político: o da fragmentação da sociedade, onde os seus vários grupos - os negros, os gays, as feministas, os judeus etc. - falam por si, escrevem a sua própria história a partir dos seus pressupostos, e onde nada precisa ser provado. O problema, no meu entender, não é negar o "conhecimento localizado", mas somá-lo como ponto de partida e ir para além dele em busca de uma comunicação possível, em busca de um conhecimento que possa ser provado e aceito, mesmo quando envolver verdades desagradáveis e dolorosas. (PALLARES-BURKE, 2000, p. 298-299).

Este problema teórico lançado pelo historiador italiano nos coloca, primeiramente, diante de um falso postulado que lhe é atribuído: a de ser um intelectual "pós-moderno". Nada mais avesso a voga pós-moderna do que o alerta de Ginzburg sobre os riscos da fragmentação do conhecimento histórico. E, numa outra chave de análise, o vemos dialogar (ainda que indiretamente) com a dialética marxista, na medida em que convida o historiador a "ir para além" do conhecimento localizado (fragmentado) na busca/prova da verdade, propondo "uma comunicação possível" com outros contextos, sujeitos e determinações históricas. Por este ângulo, existe no historiador italiano uma certa preocupação - tão cara a Marx (e os marxismos) - em reconstruir a "totalidade histórica". Contudo, é preciso considerar que dita "totalidade" é reivindicada em seus escritos através de uma mediação teórico-metodológica com o conceito-metáfora de "ruína" em Walter Benjamin (2007; 2012) $)^{4}$.

Um terceiro ponto de clivagem na análise ginzburguiana sobre retórica e prova diz respeito à crítica feita a Nietzsche e, principalmente, a Foucault acerca do nexo entre conhecimento e poder e da impossibilidade de se atribuir sentidos de "prova" ao exercício retórico (narrativo/discursivo). Afirma o próprio Carlo Ginzburg:

[...] ao avaliar as provas, os historiadores deveriam recordar que todo ponto de vista sobre a realidade, além de ser intrinsecamente seletivo e parcial, depende das relações de força que condicionam, por meio da possibilidade de acesso à documentação, a imagem total que uma sociedade deixa de si. Para 'escovar a história ao contrário', como Walter Benjamin exortava a fazer, é preciso aprender a ler os testemunhos às avessas, contra as intenções de quem os produziu. Só dessa maneira será possível levar em conta tanto as relações de força, quanto aquilo que é irredutível a elas. (GINZBURG, 2002, p. 43).

Interessante notar que o conceito de "relações de força" em Ginzburg aproxima-se do de "condições de produção" em Pêcheux (ou em Orlandi). Ambos referem-se a condicionantes externos ("contextos"), que formam e conformam os discursos presentes nos testemunhos/textos. Também há uma aproximação no que tange a apropriação

\footnotetext{
4 Tanto nas "Passagens", quanto em textos como "O narrador" e "Teses sobre o conceito de História", Benjamin trabalhou, pelo viés da memória, com a (re)construção da experiência e do conhecimento históricos, ao lado da forte presença do messianismo judaico em sua perspectiva de "salvação". Assim, o filósofo alemão cria na necessidade (e vontade) imperiosa do historiador (narrador) de partir dos fragmentos/ruínas "esquecidos/as" ("cristalizados") no tempo para, através de procedimentos dialéticos caros a modernidade burguesa (por exemplo, o uso e apelo das imagens) buscar apreender e restituir ("salvar") - em meio ao movimento dinâmico da história - uma visão de mundo mais completa ou mais próxima da "totalidade" (pra ele, sempre inacabada e inconclusa). Para nós, é evidente a influência de Benjamin na formação intelectual de Ginzburg. (BENJAMIN, 2007; 2012).
} 
benjaminiana da leitura das evidências históricas "às avessas", isto é, "contra as intenções de quem os produziu". Um contra-discurso ou um interdiscurso, diria Pêcheux; a tentativa de se chegar a uma "prova retórica", diria Ginzburg.

Contudo, é justamente aí que um conceito separa o ponto de vista de Carlo Ginzburg da Análise de Discurso de Pêcheux: o problema da "verdade". Se, por um lado, as teorias da $A D$ costumam desconsiderar a pretensão de verdade nos textos - segundo Orlandi (2013, p. 26), a AD "não procura um sentido verdadeiro através de uma 'chave' de interpretação... (pois) Não há uma verdade oculta atrás dos textos" - de outro, os escritos de Ginzburg têm percorrido caminho inverso, ainda que incorporando as contribuições dos diversos domínios da Linguagem.

Para o historiador italiano, a ressignificação do conhecimento verdadeiro na escrita histórica passa necessariamente pelo valor heurístico atribuído às narrativas históricas e ficcionais e os modos pelos quais elas, numa perspectiva dialética, possibilitam uma gama variada de acessos ao "Outro" no tempo e ao que chamamos de "passado". Com quê objetivo? Problematizar a tese de Nietzsche (e seus discípulos) - cujas raízes remontam a uma leitura moderna de Cícero e Tucídides - segundo a qual "a pretensão do homem de conhecer a verdade, além de ser efêmera, é também ilusória", posto que comprometida pela "regularidade da linguagem". (GINZBURG, 2002, p. 23).

A concepção estética (e radical) da linguagem em Nietzsche, que desemboca nas concepções de "estilo" e "gosto", define a verdade enquanto um "exército móbil de metáforas" ou "metáforas que se esgarçaram e perderam toda forma sensível" (GINZBURG, 2002, p. 24): assim, caberia ao homem moderno concluir que, no jogo ilusório das verdades aparentes perpetradas pela retórica, sua tarefa principal (e, talvez, única) seria a de interpretar fatos como quem "resgata" discursos - fragmentados e desconexos já ditos e independentes da historicidade do tempo.

Aí reside o perigo do ceticismo moral, especialmente quando entronizado nos domínios da linguagem e da narrativa, ao qual Ginzburg procura distanciar-se. Sua concepção de "prova retórica" consiste num pressuposto de entendimento das narrativas históricas enquanto possibilidades de construção de conhecimentos situados, mas cujo sentido aponta para a busca da verdade (e da "objetividade") - mesmo que tal sentido de busca seja "intrinsecamente seletivo e parcial”. (GINZBURG, 2002, p. 43).

Mesmo sabedor de que uma narrativa histórica é constituída pela subjetividade, criatividade e imaginação do historiador no processo de (re)construir os fios e os rastros de uma sociedade, uma classe, uma comunidade, um indivíduo no tempo (ou tempos), Ginzburg reconhece o papel fundante dos modelos narrativos em todas as etapas de uma pesquisa histórica, ao criar interdições e abrir novas possibilidades de conhecimento, isto é, de que "[...] a projeção do desejo, sem o qual não há pesquisa, não é incompatível com os desmentidos infligidos pelo princípio de realidade. $O$ conhecimento (mesmo 0 conhecimento histórico) é possível”. (GINZBURG, 2002, p. 45).

Portanto, ao contrário do que formulou Saviani em sua conferência - quando, a certa altura, associou a "persistência da História como narrativa" com o "caráter de gênero literário" e "a diretriz positivista de descrição fiel dos fatos" (1997, p. 12) - Ginzburg demonstra, num diálogo possível entre história e literatura e bem distante de dogmas positivistas, que a busca da verdade se torna possível.

Mas de um modo peculiar: o que nos faz reportar ao paradigma indiciário através 
de conhecida afirmação de Aby Warburg, citada por Ginzburg (2007a, p. 143): "Deus está no particular". Em outras palavras, para que a verdade do (e no) conhecimento histórico reconquiste sua legitimidade científica, será necessário pensá-la como um ponto de chegada, e não de partida, já que os limites entre o verdadeiro, o fictício e o falso são tênues, porém delimitáveis pelas chamadas "zonas opacas" - "alguns dos rastros que um texto (qualquer texto) deixa atrás de si”. (GINZBURG, 2007b, p. 12).

São esses "rastros", ou dados negligenciáveis, que permitem ao historiador afeito ao indiciarismo construir narrativas passíveis de ir além da própria narratividade e comprometer-se com o problema da verdade - desde que historicamente situada e determinada. $E$ isto, assinalou Ginzburg, "mesmo quando envolver verdades desagradáveis e dolorosas". (PALLARES-BURKE, 2000, p. 299).

\section{Considerações finais}

Ginzburg é autor de obras de grande difusão mundial - o que o tornou conhecido do grande público, especialmente no Brasil. Contudo, certos aspectos do arcabouço teórico-metodológico erigidos por este historiador italiano parecem merecer maior atenção, especialmente quando apropriado por campos de estudos específicos, caso da História da Educação.

Apesar de ser considerado um nome fundamental da Micro-História (VAINFAS, 2002; LIMA, 2006) e estabelecer mediações teóricas e metodológicas com a produção historiográfica dos Annales, não se pode rotulá-lo categoricamente de pertencer a "(Nova?) História Cultural" (e tampouco de intelectual "pós-moderno"): trata-se de um reducionismo axiológico, que não apenas fragmenta o conhecimento histórico, como encerra-o numa falsa autonomia da cultura.

Se fizermos uma analogia com a seara marxista, Ginzburg estaria num mesmo espectro intelectivo de Mikhail Bakhtin e Walter Benjamin. Benjamin e Bakhtin podem ser considerados dois dos grandes intelectuais do marxismo que se dedicaram ao estudo do vasto e complexo domínio da "cultura" (literatura, teatro, cinema, poesia, pintura, fotografia, incluindo o campo da estética) e da "cultura das classes subalternas" - expressão usada por Ginzburg - nas suas relações/mediações com os movimentos da história: destaque para as amplas e meticulosas análises da linguagem em perspectiva dialética e dialógica. Não por acaso, Benjamin e Bakhtin são duas notórias referências na trajetória do historiador italiano em questão.

Considerando as "pistas" deixadas por Dermeval Saviani há vinte anos e a dilatação vivida pelo campo da História da Educação (daí a multiplicidade de temas, abordagens e metodologias) desde então, parece oportuno considerar as contribuições proporcionadas pela obra de Carlo Ginzburg, especialmente no que tange as reflexões teóricometodológicas contidas no "paradigma indiciário", tendo em vista a problematização diferente que apresenta da relação entre linguagem, história e verdade.

\section{Referencias}

ABREU, Alzira Alves de; GOMES, Ângela de Castro; OLIVEIRA, Lúcia Lippi. História e Cultura: conversa com Carlo Ginzburg. Estudos Históricos, Rio de Janeiro, v. 3, n. 6, p. 254-263, 1990. 
BAKHTIN, Mikhail. Cultura Popular na Idade Média e no Renascimento: o contexto de François Rabelais. Trad. Yara F. Vieira. São Paulo: Hucitec; Brasília: Ed. UnB, 1987.

BARROS, José D'A. Tempo e narrativa em Paul Ricoeur: considerações sobre o círculo hermenêutico. Fênix, Uberlândia, Revista do Programa de Pós-Graduação de História, Universidade Federal de Uberlândia, v. 9, n. 1, ano IX, p. 01-27, jan./abr. 2012.

BENJAMIN, Walter. Magia e técnica, arte e política. Trad. Sérgio P. Rouanet. São Paulo: Brasiliense, v. 1, 2012.

. Passagens. Trad. Irene Aron. Belo Horizonte: Editora UFMG; São Paulo: Imprensa oficial, 2007.

BLOCH, Marc. Introdução à história. Trad. Maria Manuel e Rui Grácio. Lisboa: Publicações Europa-América, s/d.

BOBBIO, Norberto. Tre maestri: Umberto Cosmo, Arturo Segre, Zino Zini In: Etica e politica - Scritti di impegno civile. Milano: Mondadori, 2013.

BOURDIEU, Pierre; PASSERON, Jean-Claude. A reprodução: elementos para uma teoria do sistema de ensino. Trad. de Reynaldo Bairão. Rio de Janeiro: Francisco Alves, 1975.

BRITO, Luiz André Neves de. (Re) Lendo Michel Pêcheux: como a análise do discurso de linha francesa apreende a materialidade discursiva? Eutomia, Revista de Literatura e Linguistica, Universidade Federal de Pernambuco, v. 9, Ano V, p. 542-562, jul. 2012.

BURKE, Peter. A Escola dos Annales (1929-1989): a Revolução Francesa da Historiografia. Trad. Nilo Odalia. São Paulo: Fundação Editora da UNESP, 1997.

Editor, 2005.

0 que é história cultural? Trad. Sérgio G. de Paula. Rio de Janeiro: Jorge Zahar

CASTANHO, Sérgio. Teoria da história e história da educação: por uma história cultural não culturalista. Campinas: Autores Associados, 2010.

COELHO, Claudio Márcio. Carlo Ginzburg: História e Indiciarismo In: RODRIGUES, Márcia Barros Ferreira (Org.). Exercícios de indiciarismo. Vitória: GM Gráfica \& Editora, 2006, v. 6, p. 65-92.

DOMITROVIC, Maria Cristina. Análise de discurso materialista e a metodologia.

Entremeios, Pouso Alegre (MG), Revista do Programa de Pós-Graduação em Ciências da Linguagem, Universidade do Vale do Sapucaí, v. 2, n. 1, p. 01-09, jan. 2011.

DOSSE, François. História do estruturalismo, v. 1: O campo do signo - 1945/1966. Trad. Álvaro Cabral; revisão técnica de Marcia Mansor D’Alessio. Bauru: Edusc, 2007a.

História do estruturalismo, v. 2: O canto do cisne - de 1967 a nossos dias. Trad. Álvaro Cabral; revisão técnica de Marcia Mansor D'Alessio. Bauru: Edusc, 2007b.

DUARTE, Cristiane. Uma análise de procedimentos de leitura baseada no paradigma indiciário. 1998, 167 f. Dissertação (Mestrado em Lingüística) - Instituto de Estudos da Linguagem, Universidade Estadual de Campinas/UNICAMP, Campinas, 1998.

FONTANA, Josep. Os marxismos In: . A história dos homens. Trad. Heloisa Reichel e Marcelo Fernando da Costa. Bauru: EDUSC, 2004. p. 309-341.

GADAMER, Hans-Georg. Verdade e método. Trad. Flávio Meurer. Petrópolis: Vozes, 1999.

GADET, Françoise; HAK, Toni. Por uma análise automática do discurso: uma introdução a obra de Michel Pêcheux. Trad. Bethania S. Mariani. (et al.). Campinas: 
Editora da UNICAMP, 1997.

GINZBURG, Carlo. Micro-história e outros ensaios. Trad. Antônio Narino. Rio de Janeiro: DIFEL/Bertrand-Brasil, 1989.

. Mitos, emblemas, sinais: morfologia e história. Trad. Federico Carotti. São Paulo: Companhia das Letras, 2007a.

O fio e os rastros: verdadeiro, falso, fictício. Trad. Rosa F. D'Aguiar e Eduardo Brandão. São Paulo: Companhia das Letras, 2007b.

O queijo e os vermes: o cotidiano e as idéias de um moleiro perseguido pela Inquisição. Trad. Maria B. Amoroso. São Paulo: Companhia das Letras, 2006.

Relações de força: história, retórica, prova. Trad. Jônatas B. Neto. São Paulo: Companhia das Letras, 2002.

GRAMSCI, Antonio. Cadernos do cárcere. v. 4. Trad. Carlos N. Coutinho e Luis S. Henriques. Rio de Janeiro: Civilização Brasileira, 2001.

GREGOLIN, Maria do Rosário. Análise do discurso e mídia: a (re)produção de identidades. Comunicação, mídia e consumo, São Paulo, v. 4, n. 11, p. 11-25, nov. 2007.

GRONDIN, Jean. Hermenêutica. Trad. Marcos Marcionilo. São Paulo: Parábola Editorial, 2012.

HOBSBAWM, Eric. Marx e a História In: Paulo: Companhia das Letras, 1998. p. 171-184.

Sobre História. Trad. Cid K. Moreira. São

HUNT, Lynn (Org.). A nova história cultural. Trad. Jefferson L. Camargo. São Paulo: Martins Fontes, 1995.

LIMA, Denise Maria de Oliveira. Freud e Morelli: encontro não casual. Cogito, Salvador, Círculo Psicanalítico da Bahia, v. 8, p. 83-89, 2007.

LIMA, Henrique Espada. A micro-história italiana - escalas, indícios e singularidades. Rio de Janeiro: Record, 2006.

MARTINS, Antônio Carlos Soares. Linguagem, subjetividade e história: a contribuição de Michel Pêcheux para a constituição da análise do discurso. Unimontes Científica, Montes Claros, v. 6, n. 1, p. 01-10, jan./jun. 2004.

ORLANDI, Eni Pulcinelli. Análise de discurso: princípios e procedimentos. Campinas: Pontes Editora, 2013.

Discurso em análise: sujeito, sentido, ideologia. Campinas: Pontes, 2012.

PALLARES-BURKE, Maria Lúcia. Carlo Ginzburg. In: história: nove entrevistas. São Paulo: UNESP, 2000. p. 269-306.

PETERLE, Patrícia. A voz de Natalia Ginzburg. Revista Estudos Feministas, Florianópolis, CFCH/CCE/UFSC, v. 20, n.1, p. 332-334, jan./abr. 2012.

REIS, José Carlos. Escola dos Annales: A inovação em história. São Paulo: Paz e Terra, 2000.

RICOEUR, Paul. História e Verdade. Trad. A. Ribeiro. Rio de Janeiro: Forense, 1968.

Tempo e narrativa. Trad. Roberto L. Ferreira. São Paulo: Papirus, 1997. Tomo III. SANFELICE, José Luís. História de Instituições escolares e micro história. Revista HISTEDBR On-line, v. 39, p. 32-41, set. 2010.

SAVIANI, Dermeval. O debate teórico-metodológico da história e sua importância para a 
educação. IV Seminário Nacional de Estudos e Pesquisas "História, Sociedade e Educação". Campinas: HISTEDBR, 1997 (CD-Rom).

SAVIANI, Dermeval; LOMBARDI, José Claudinei; SANFELICE, José Luís (Org.). História e história da educação: o debate teórico-metodológico atual. Campinas: Autores Associados, 2005.

VAINFAS, Ronaldo. História das mentalidades e História cultural. In: VAINFAS, Ronaldo; CARDOSO, Ciro Flamarion. Domínios da História: ensaios de teoria e metodologia. Rio de Janeiro: Campus, 1997. p.127-162.

2002.

Micro-história: os protagonistas anônimos da história. Rio de Janeiro: Campus,

VIEIRA, Alboni Marisa Dudeque. A história cultural e as fontes de pesquisa. Revista HISTEDBR On-line, v. 61, p. 367-378, mar. 2015.

RODRIGO RIBEIRO PAZIANI é professor dos Programas de Graduação e Pós-Graduação do Colegiado de História da Universidade Estadual do Oeste do Paraná (Unioeste), Campus de Marechal Candido Rondon. Integrante do Grupo de Pesquisa CNPq "História e Poder" (Unioeste).

Endereço: Rua Pernambuco, 1777, Bairro Universitário, 85960-000, Marechal Cândido Rondon/PR, Brasil.

E-mail: rodrigo.paziani@gmail.com

HUMBERTO PERINELLI NETO é professor do Ibilce/Unesp/São José do Rio Preto e do Programa de Pós-Graduação "Ensino e Processos Formativos" (Unesp - São José do Rio Preto/Ilha Solteira e Jaboticabal). Faz parte do grupo de pesquisa CNPq "Formação Docente e Práticas Educativas" (Unesp).

Endereço: Rua Cristóvão Colombo, 2265, Jardim Nazareth, 15054-000, São José do Rio Preto/SP, Brasil.

E-mail: humberto@ibilce.unesp.br

Recebido em 05 de março de 2017.

Aceito em 29 de março de 2017. 